\title{
Study on the Laying and Protection Range of High-Rise Building Lightning Rod
}

\author{
Deying Ran \\ Shandong Yuejian Construction Group Co., Ltd, 274000, 2118 Huanghe East Road, \\ Heze City, Shandong Province, China \\ 286000837@qq.com
}

\begin{abstract}
The lightning protection principle of high-risebuilding lightning rod is analyzed. The installation of lightning rod can be divided into independent lightning rod and frame lightning rod. This paper analyzes the protection range of lightning rod from four aspects: single lightning rod, two equal height lightning rods, two unequal height lightning rods and three or more lightning rods. In this paper, the installation and protection range of lightning rod in high-rise buildings are described in detail. It is hoped that it will play a positive role in today's lightning protection production practice, for your reference.
\end{abstract}

Keywords: High-rise building, Lightning rod, Laying, Protection scope

\section{Introduction}

In modern cities, many high-rise buildings are rising, which shortens the distance between lightning and air. At the same time, due to the global warming and the increase of urban heat island phenomenon, the urban atmospheric circulation situation has new characteristics, and the thunderstorm period in summer is extended. More importantly, with the progress of science and technology, microelectronics equipment is widely used, urban communication power supply is greatly increased, and urban electromagnetic field changes, especially microelectronics products generally have low insulation strength, poor over-voltage tolerance, and are prone to lightning attack [1]. Among them, computer network, communication and command system and public antenna are all severely affected areas. In a sense, the more advanced technology, the greater the threat of lightning to people. The invention of lightning rod greatly reduces the harm of lightning to human life.

The development of lightning rod is also developing with the progress of science and technology, especially in the aspects of building lightning protection and power system lightning protection, which gradually forms some fixed specifications, which further improves the lightning protection technology for direct lightning and strong electricity [2]. Lightning rods have been widely used since Franklin's kite experiment in Philadelphia in 1752. The invention of lightning rod greatly reduces the harm of lightning to human life. With the development of science and technology, the development of lightning rod is developing constantly, especially in the aspects of building lightning protection and power system lightning protection, some fixed specifications are gradually formed, which further improves the lightning protection technology for direct lightning and strong electricity. In

Article history:

Received (March 4, 2020), Review Result (April 13, 2020), Accepted (May 14, 2020) 
recent years, with the rapid development of electronic technology, the characteristics of lightning disaster also have new changes. Many of the characteristics of lightning that have not attracted attention appear through the destruction of new electronic devices, which pose a great threat to the safety of modern electronic devices. It is precisely because of the continuous emergence of these new problems that the improvement of lightning rod technology is gradually driven.

Lightning is a kind of natural phenomenon. At present, human beings have not yet mastered and utilized it, and are still in the stage of preventing its harm. The purpose of lightning protection is electrical safety. With the increasing use of electronic systems (computers, communication equipment, etc.), in such a world relying on power grid and information system, overvoltage accidents and damages become more and more serious. With the extensive production and living practice, various effective lightning protection measures have been summarized. The main measure to prevent direct lightning is to set up lightning rod, and the protection range of lightning rod is an important index of lightning protection device. In this regard, the selection and installation of lightning rod in high-rise buildings are described in detail, hoping that it can play a positive role in today's lightning protection production practice.

\section{Brief introduction of lightning rod}

The lightning rod is used as the lightning arrester. The lightning rod is connected to the underground through the conductor and forms the equipotential difference with the ground. The electric field of the lightning which increases the electric field strength to the limit value will be distorted by using its own height, and the lightning rod will start to ionize and discharge downward; the lightning rod will discharge at the tip under the action of strong electric field; the lightning rod will discharge upward: the lightning path will be formed by the combination of the two, and the lightning rod will enter the ground to achieve the lightning protection effect. In fact, the lightning protection device is a lightning rod, which can lead the surrounding lightning and discharge in advance, and transmit the lightning current to the ground through its own grounding conductor, so as to avoid the protection object being directly struck by lightning. The installed lightning rod and conductor shall have good conductivity, and the grounding grid shall ensure the minimum impedance value [3].

The protection function of the lightning rod is that in the pilot discharge stage, the top of the lightning rod accumulates electric charge. At this time, there is a high electric field strength in the air gap between the developing pilot and the lightning rod. The occurrence and development of the face-to-face pilot on the lightning rod strengthen the electric field strength in the gap, so as to finally make the lightning strike on the lightning rod. Because it is shielded by the lightning rod and the face-to-face leader, the protected objects that are lower than the lightning rod and distributed nearby will not be hit by the lightning in fact. On the average, many countries in the world have changed from geometry method to electrical geometry method since 1981. This is the general trend. According to the shielding failure event records, the electrical geometry method is superior to the geometry method [4].

For lightning rod, good grounding is the premise to prevent counterattack and ensure its function. There are two characteristics of lightning protection grounding and general grounding: one is the large amplitude of lightning current, the other is the high equivalent frequency of lightning current. The large amplitude of lightning current will increase the current density in the ground, so the electric field strength in the ground will be improved, especially near the surface of the grounding body. When the ground electric field strength is 
higher than the breakdown field strength of soil, partial spark discharge will occur, which will increase the conductivity of soil. The results show that when the soil resistivity is about 500 $\Omega \cdot \mathrm{m}$ and the pre discharge time is $3-5 \mu \mathrm{s}$, the breakdown field strength of the soil is $6-12 \mathrm{kv} /$ $\mathrm{cm}$. Therefore, under the action of lightning impulse current with high amplitude, the grounding resistance of the same grounding device is smaller than the value under power frequency current, which is called spark effect [5]. The high equivalent frequency of lightning current will make the grounding body present obvious inductive effect, and hinder the current flow to the far end of the grounding body. This effect is more significant for the larger length of grounding body. As a result, the grounding body is not fully utilized, and the grounding resistance is greater than the power frequency grounding resistance, which is called inductance effect [6]. For the lightning rod, not only the protected object should be within the protection range of the lightning rod, but also the lightning rod should not be struck back.

\section{Installation of lightning rod}

The installation of lightning rod can be divided into independent lightning rod and frame lightning rod. The frame lightning rod has the advantages of low cost and easy layout. However, as the framework is close to the electrical equipment, more attention should be paid to meet the requirements of no counterattack. For distribution equipment of $110 \mathrm{kV}$ and above, due to the high insulation level of electrical equipment, it is not easy to have counterattack in areas with low soil resistivity, so it is generally allowed to install lightning rod on the framework of distribution equipment. However, in the area with soil resistivity greater than $1000 \Omega \cdot \mathrm{m}$, it is not suitable to install frame lightning rod.

The frame with lightning rod shall also be equipped with auxiliary centralized grounding device nearby. The electrical distance between the connection point of auxiliary grounding device and substation grounding grid and the connection point of main transformer and grounding grid shall not be less than $15 \mathrm{~m}$. In this way, when lightning strikes the lightning rod, the high potential voltage wave generated on the grounding device, after the propagation attenuation of this distance, reaches the grounding point of the transformer, its amplitude has been reduced to not cause counterattack to the transformer. The transformer is the most important equipment in the substation. In order to ensure its safety, it is not allowed to install lightning rod on the door frame of the transformer [7].

With the development of national economic construction, the disaster caused by lightning is more and more serious, the frequency of lightning disaster is higher and higher in all industries, and the economic loss is also increasing year by year, especially the high-rise buildings, inflammable and explosive places, computers and their sites are very vulnerable to lightning attack. It is very important to take lightning protection design to prevent buildings from lightning disaster and ensure the safety of electrical equipment and people. Through the above methods, we can accurately calculate the scope of lightning protection, effectively protect equipment, reduce economic loss and avoid casualties. As a designer, we should pay more attention to the summary and accumulation in the usual work practice, and constantly improve and perfect, so that the design concept can be fully implemented in the project.

The safety performance of the building is the guarantee of the normal use of the building. We must do a good job in the lightning protection and grounding installation of the high-rise building, and take reasonable and effective construction technology and measures in combination with the actual situation, do a good job in the quality management of the whole construction process, timely solve the problems encountered, and constantly summarize the experience, so as to truly improve the construction quality of the lightning protection and 
grounding installation of the building, Ensure the safety performance of the building. The safety performance of the building is the guarantee of the normal use of the building. We must do a good job in the lightning protection and grounding installation of the high-rise building, and take reasonable and effective construction technology and measures in combination with the actual situation, do a good job in the quality management of the whole construction process, timely solve the problems encountered, and constantly summarize the experience, so as to truly improve the construction quality of the lightning protection and grounding installation of the building, ensure the safety performance of the building.

\section{Protection range of lightning rod}

The protection scope refers to the space around the lightning protection device, which is rarely hit by lightning flash. In this way, the protected objects should be placed completely within the boundary of the protection scope. It should be emphasized that the so-called "protection scope" is only of relative significance, and it cannot be considered that objects within the protection scope are safe and will not be directly hit by lightning, nor that objects outside the protection scope will not be completely protected by lightning arresters. Therefore, a shielding rate should be specified for the protection scope. The so-called shielding refers to the phenomenon that lightning bypasses the lightning protection device and hits the protected object. Obviously, different protection range can be obtained from different round attack rate. The protection range recommended by relevant regulations of our country corresponds to $0.1 \%$ of the round failure rate, so the small round failure rate can be generally considered that its protection effect is reliable enough. Some countries also provide different protection ranges for designers according to different shielding rates [8][9][10]. The protection range of the lightning rod recommended by the relevant standards of our country is based on a large number of simulation test results are obtained after many years of practical operation experience verification.

\subsection{Basic principle of shielding calculation by traditional method and strike distance method}

Traditional shielding calculation is based on experience and simulation test under small lightning impulse current to determine the protection range of lightning rod and lightning wire. For example, a lightning rod protects a cone. Of course, the protection range associated with the protection function is not a function of the simple proportion of the height to the radius of the cone, but a probability function. The protection range of lightning rod in China is determined by the simulation test under the condition of small lightning impulse current (regardless of its specific value), and verified by operation experience. The test is to determine the protection range according to the protection probability of $99.9 \%$ (i.e. shielding failure rate or shielding failure rate of $0.1 \%$ ), and the radius of the cone on the ground is $1.5 \mathrm{~h}$. The protection mechanism is that when the thundercloud moves randomly, the lightning leader develops randomly in any direction, and its direction is not affected by the ground objects [11]. However, when the pilot reaches a certain $\mathrm{H}$ value, the grounded object causes obvious distortion of the electric field, and leads the direction of the maximum field strength, that is, the direction of the development of the discharge, to the nearest grounded object. The height day from which the earth object is oriented is called the directional height $h$, which is called the directional height.

For more than ten years, there is a new view on the development of lightning discharge and shielding mechanism abroad, that is, the orientation process and shielding effect are affected 
by the amount of charge and the magnitude of lightning current. The analysis is based on the concept of flash distance, which is the distance between the leader and the target. Under this distance, the average electric field intensity reaches its critical breakdown value, and the mid point of the strike is uncertain until the leader reaches the flash distance. When the flash distance is reached, the stream column is fired from the ground target to meet the leader. The critical average electric field intensity has been estimated by different researchers as 3-6 kV/ $\mathrm{cm}$. The flashover distance is related to the charge in the leader, which in turn determines the magnitude I of the lightning current.

\subsection{Determining the protection range of lightning rod with electrical geometry model}

In the past, it was thought that only when the lightning leader developed from thundercloud to a certain height $\mathrm{h}$, the electric field near the lightning rod on the ground would have obvious distortion, so that the leader would develop towards the lightning rod [12]. $\mathrm{H}$ is called the directional height. In order to determine the protection range of lightning rod by simulation test, the high voltage electrode of impulse voltage generator simulating lightning leader is put on the height of $\mathrm{h}$ for test. Obviously, there is a great relationship between the test results and the selection of $\mathrm{H}$ value. In the past simulation test, $\mathrm{h}$ and lightning protection are considered

In the past 20 years, with the deepening of the research on the shielding effect of the transmission line lightning conductor, a new method, electrical geometric model, has emerged to study the shielding effect by applying the concept of strike distance and geometric drawing method. The so-called electrical geometric model refers to a geometric analysis and calculation model established by connecting the lightning discharge characteristics with the line structure size. Its basic principle is based on the following basic concepts and assumptions.

(1) The critical breakdown distance from the head of the pilot discharge channel developed from the thundercloud to the ground to the hit object before the strike distance, the strike midpoint is uncertain. The first thing to reach within the strike distance is to discharge the object.

(2) The strike distance is related to the potential of the leader's head, so it is related to the charge density of the pilot channel. The latter determines the amplitude of lightning current, so the strike distance is a function of the amplitude of lightning current.

(3) It is assumed that the strike the distance of the leader to the tower, the lightning wire and the conductor is equal without considering the influence of other factors such as the shape of the lightning target object and the proximity effect on the strike distance. Originally, Whitehead et al. Considered that the average breakdown electric field strength of the pilot to the ground may be different from that of the lightning conductor and conductor, the strike distance to the ground was taken as the strike distance conversion coefficient, which needs to be determined by the field experience.

(4) It is assumed that the incident angle of the pilot approaching the ground obeys a given probability distribution function, with the maximum vertical lightning density and the minimum horizontal lightning density. The specific distribution function is determined according to the field experience.

In addition, the influence of ground inclination angle should also be considered. The average height of conductor and ground wire to the ground in the span should be taken for analysis, and sometimes the influence of wind speed should be taken into account [13].The so-called strike distance refers to the distance that the pilot directly strikes the ground target 
according to the shortest path in the final stage of development. The strike distance is related to the potential of the pilot head, so it is related to the amount of charge and the expected amplitude of lightning current. In this way, the protection range is a concept related to the magnitude of lightning current. The larger the amplitude of lightning current is, the larger the lightning absorption and protection range of lightning rod is. On the contrary, for the lightning current with small amplitude, the protection range will also be reduced. In the past, these relationships were not considered in the simulation test of protection range.

\subsection{Classification}

The protection scope of a single lightning rod is a curved cone with its body as its axis, like a round tent. In order to increase the protection range, it is not a good idea to increase the height of lightning rod. The reasonable solution is to use multiple lightning rods as joint protection. The total protection range of two equal height lightning rods is not simply the sum of the protection range of two single lightning rods, but the protection range between the two rods is expanded, but the protection range outside the two rods is still determined according to the calculation method of single lightning rod [14]. The protection range of two lightning rods with unequal height can be determined according to the following method: firstly, the protection range of two single rods shall be made respectively, then a horizontal line shall be made from the top of the low rod 2, and the boundary of the protection range of the high rod 1 shall be intersected at point 3, then point 3 shall be taken as the top of an imaginary equal height lightning rod, and the joint protection range of equal height lightning rod 2 and 3 can be obtained to obtain the total protection range. The joint protection range of the three lightning rods can be calculated according to different combinations of each two rods [15]. As long as it is on the horizontal plane of the height of the protected object, the middle part of the triangle composed of three rods can be jointly protected by three rods. When there are four or more needles, the protection range can be calculated according to different combinations of each three needles, and then the total combined protection range can be obtained by superposition.

\section{Conclusion}

The principle of lightning rod protection and the calculation method of protection range are described in detail. The installation of lightning rod can be divided into independent lightning rod and frame lightning rod. This paper analyzes the protection range of lightning rod from four aspects: single lightning rod, two equal height lightning rods, two unequal height lightning rods and three or more lightning rods. With the development of national economic construction, the disaster caused by lightning is more and more serious. The frequency of lightning disaster in construction industry is higher and higher. The economic loss is also increasing year by year, especially the high-rise buildings in the city are very vulnerable to lightning attack. Therefore, it is particularly important to take lightning protection design to prevent the buildings from lightning disaster and ensure the safety of electrical equipment and people. Through the above methods, the lightning protection range can be accurately calculated, the equipment can be effectively protected, the economic loss can be reduced and people can be avoided Casualties. As a designer, we should pay more attention to summary and accumulation in our daily work practice, improve and perfect constantly, so that the design concept can be fully implemented in the project

\section{References}


[1] Holzwarth C W, Barwicz T, and Smith H I., "Optimization of hydrogen silsesquioxane for photonic applications," Journal of Vacuum Science \& Technology B, vol.25, no.6, pp.2658-2661, (2007) DOI: $10.1116 / 1.2787832$

[2] Liu Xiao-dong, Li Song-ru, and Feng Xu-yu, et al., "Design and implementation of software system in lightning protection device design check and accept," Computer \& Modernization, vol.1, no.8, pp.74-76,8, (2011) DOI: 10.3969/j.issn.1006-2475.2011.08.021

[3] Serdar Yilmaza, Bekir Kavicib, and Cigdem Celenb, et al., "Structure and conductivity characterization of new type ionic conductor stabilized bismuth oxide ternary systems," Chinese Journal of Physics- Taipei-, vol.56, no.1, pp.362, (2018) DOI: 10.1016/j.cjph.2017.11.010

[4] Zhaoran Zhang, Dena Guo, and Meghan E. Huber et al., "Exploiting the geometry of the solution space to reduce sensitivity to neuromotor noise," Plos Computational Biology, vol.14, no.2, e1006013, (2018) DOI: 10.1371/journal.pcbi.1006013

[5] Jia, Chao, Hu, Zhijian, Fang, and Jiacheng, "Repeated synchronous non-power-frequency method for measuring grounding resistance of grounding grid," Electric Power Automation Equipment, vol.35, no.4, pp.167-172, (2015) DOI: 10.16081/j.issn.1006-6047.2015.04.026

[6] Tibor Magura, Gábor L. Lövei, "Environmental filtering is the main assembly rule of ground beetles in the forest and its edge but not in the adjacent grassland," Insect Science, vol.26, pp.154-163, (2019) DOI: 10.1111/1744-7917.12504

[7] Lv Shi X., "Exploration of the rockwork controlled blasting closed to the existing railways and its safety precautions," Applied Mechanics and Materials, pp.193-194, pp.796-800, (2012) DOI: 10.4028/www.scientific.net/AMM.193-194.796

[8] C. Dharma Raj, M.V.S.L. Ramyasree, and V. Sravan Kumar, "Analysis of wire mesh screen for shielding effectiveness in different frequency ranges," Computer, Communication and Electrical Technology (ICCCET), 2011 International Conference on, (2011) DOI: 10.1109/ICCCET.2011.5762467

[9] Erkan Gunpinar a Serkan Gunpinar, "A shape sampling technique via particle tracing for CAD models," Graphical Models, vol.96, pp.11-29, (2018) DOI: 10.1016/j.gmod.2018.01.003

[10] Kurudirek M., "Radiation shielding and effective atomic number studies in different types of shielding concretes, lead base and non-lead base glass systems for total electron interaction: A comparative study," Nuclear Engineering \& Design, vol.280, pp.440-448, (2014) DOI: 10.1016/j.nucengdes.2014.09.020

[11] Sima W, Fan S, and Yang Q, et al., "Modelling of the inhibition effect of thin-wire ultra-corona on upward leader and its application on lightning protection in high-voltage transmission lines," Generation Transmission \& Distribution Iet, vol.8, no.5, pp.935-944, (2014) DOI: 10.1049/iet-gtd.2013.0294

[12] Chen Weijiang, He Hengxin, and HE Junjia, et al., "On the 3-Dimentional leader progression model for the lightning shielding failure performance estimation of overhead transmission lines," Proceedings of the CSEE, vol.34, no.36, pp.6601-6612, (2014) DOI: 10.13334/j.0258-8013.pcsee.2014.36.029

[13] Avci M, and Yazici M Y., "An experimental study on effect of inclination angle on the performance of a PCM-based flat-type heat sink," Applied Thermal Engineering, vol.131, pp.806-814, (2018) DOI: 10.1016/j.applthermaleng.2017.12.069

[14] Wu, H, Zhang, X, and Luo, W, et al., "A compact double-exponential current generator based on the cage cavity consisted of multisteel rods," IEEE Transactions on Plasma Science, (2018) DOI: 10.1109/TPS.2018.2793259

[15] Tarlock A D., "United states flood control policy: the incomplete transition from the illusion of total protection to risk management," vol.23, no.1, pp.377-390, (2012) DOI: 10.1016/j.ymssp.2011.10.014 
Study on the Laying and Protection Range of High-Rise Building Lightning Rod

This page is empty by intention. 